\title{
Conformal Titanyl Phosphate Surface Passivation for Enhancing Photocatalytic Activity
}

\author{
Jung Kyu Kim ${ }^{10}$ \\ School of Chemical Engineering, Sungkyunkwan University (SKKU), Suwon 16419, Korea; legkim@skku.edu \\ Received: 30 July 2018; Accepted: 17 August 2018; Published: 19 August 2018

\begin{abstract}
A conformal titanyl phosphate passivation with the thickness of ca. $5 \mathrm{~nm}$ on the surface of $\mathrm{TiO}_{2}$ nanoparticles for enhancing the photocatalytic degradation of organic pollutants and hydrogen production is described. The phosphate anion species bound to the surface of $\mathrm{TiO}_{2}$ promote the favorable kinetics of photocatalytic activity and influence the catalytic reaction pathway. By using a facile surfactant-assisted sol-gel process, the surface defects of $\mathrm{TiO}_{2}$ associated with deep traps was reduced and passivated by the phosphate anion species to form the titanyl phosphate. The strong bonds between the titanyl phosphate shell and $\mathrm{TiO}_{2}$ core provided a long-term photochemical stability in aqueous electrolytes with enhanced photocatalytic activities. The titanyl phosphate contributed to the production and stabilization of hydroxyl radicals on the surface of photocatalyst, which facilitated the efficient photooxidation of the organic pollutants. Further, enhancing the photocatalytic hydrogen production was achieved by the titanyl phosphate modified $\mathrm{TiO}_{2}\left(\mathrm{TP}-\mathrm{TiO}_{2}\right)$. Consequently, the conformal titanyl phosphate passivation enhanced photocatalytic activity of $\mathrm{TiO}_{2}$. Comparing to the bare $\mathrm{TiO}_{2}$ nanoparticles, approximately two-fold higher photocatalytic $\mathrm{H}_{2}$ production rate was achieved by the $\mathrm{TP}-\mathrm{TiO}_{2}$.
\end{abstract}

Keywords: titanyl phosphate; passivation of defects; stability; hydrogen production; photodegradation of pollutant

\section{Introduction}

Titanium dioxide $\left(\mathrm{TiO}_{2}\right)$ is the most extensively studied metal oxide semiconductor used for diverse solar energy conversions including photovoltaics, photodegradation of organic pollutants, and photocatalytic hydrogen production [1-11]. As for the promising heterogeneous photocatalyst, numerous efforts have been conducted to enhance the photocatalytic activity of $\mathrm{TiO}_{2}$ nanoparticles by modifying their surface properties [12]. Despite numerous advantages of $\mathrm{TiO}_{2}$, the tremendous intrinsic defect states in $\mathrm{TiO}_{2}$ can deteriorate the charge transfer performance of photocatalysis. The deeply localized defects in $\mathrm{TiO}_{2}$ can act as undesired charge trap centers and promote the rapid charge recombination [13-15]. These defect states and deep traps induce the crucial charge losses [16,17].

In recent years, numerous efforts have been conducted to enhance the photocatalytic activity of $\mathrm{TiO}_{2}$ nanoparticles by modifying their surface properties with phosphate anion $\left(\mathrm{PO}_{4}^{3-}\right)$ [18-22] The surface modification using the phosphate species can generate the negative electrostatic field at the interface. This preferred surface electrostatic field facilitates the efficient charge separation and prolongs the photo-induced charge migration $[20,22]$. In addition, the negative electrostatic field can activate the formation of hydrogen bonds between phosphate anions and water molecules. Thereby, the phosphate species bound on $\mathrm{TiO}_{2}$ can promote the generation of hydroxyl radicals, resulting in the highly efficient photocatalytic degradation of organic pollutants [23]. However, the photochemical conversion efficiency can be weakened since the direct hole oxidation pathway can be hindered by the hydroxyl radicals. The adsorbed phosphate anion on the surface of $\mathrm{TiO}_{2}$ also can increase the 
resistance of electron transfer at the interface [24,25]. Therefore, a rational design of the phosphate modification is strongly required for efficient $\mathrm{TiO}_{2}$ photocatalysis.

In this study, the $\mathrm{TiO}_{2}$ nanoparticles were conformally modified by the titanyl phosphate passivation layer with a thickness of ca. $5 \mathrm{~nm}$. The use of a facile surfactant-assisted sol-gel process with titanium isopropoxide, phosphoric acid, and polyethylene glycol as a surfactant facilitated the formation of titanyl phosphate because the phosphate anion can strongly bind the surface Ti atom with the oxygen bridge, inducing the Ti-O-P-O bonds [26]. The titanyl phosphate passivated the surface defects in $\mathrm{TiO}_{2}$ and reduced the deep traps associated with $\mathrm{Ti}^{3+}$. Consequently, the titanyl phosphate modified $\mathrm{TiO}_{2}\left(\mathrm{TP}-\mathrm{TiO}_{2}\right)$ shows significantly enhanced photocatalytic activities through the photocatalytic degradation of organic pollutant (rhodamine B) and hydrogen production experiments.

\section{Materials and Methods}

\subsection{Material Synthesis}

The facile surfactant assisted sol-gel process was conducted by using titanium(IV) isopropoxide (TTIP, 97\%, Aldrich), polyethylene glycol (PEG, $\mathrm{M}_{\mathrm{n}}$ 300, Aldrich), phosphoric acid (85 wt \%, Aldich) and methyl alcohol (anhydrous, Aldrich). The titanium precursor solution with concentration of $0.35 \mathrm{M}$ was prepared by dropping the TTIP in the methyl alcohol solvent slowly (with the rate of $1 \mu \mathrm{L} / \mathrm{s}$ ) during the vigorous stirring over $600 \mathrm{rpm}$. After fully dissolving, 3.5 M PEG was immediately injected in the precursor. Then, $0.1 \mathrm{M}$ phosphoric acid was mixed with the solution. The thermal annealing process at $750{ }^{\circ} \mathrm{C}$ for $2 \mathrm{~h}$ was carried out to obtain the $\mathrm{TP}-\mathrm{TiO}_{2}$. For the bare $\mathrm{TiO}_{2}$, the same experimental protocol was utilized without the phosphoric acid.

\subsection{Material Characterization}

The particle morphologies were confirmed by X-ray diffraction (XRD) by using Siemens diffractometer D500/5000 in Bragg-Brentano geometry under $\mathrm{Cu} \mathrm{K} \alpha$ radiation and scanning electron microscopy (SEM) by using JSM-7000F. High resolution-transmission electron microscopy (HR-TEM) images and elemental mapping images were obtained from a JEOL (JEM-2100F, Japan) electron microscope with an energy dispersive spectrometer (EDS). XPS characterization was performed with ESCA2000 from VG Microtech.

\subsection{Photocatalytic Activity}

Photocatalytic degradation of organic pollutant was demonstrated by using $0.01 \mathrm{M}$ rhodamine $\mathrm{B}$ (Rh. B) aqueous solution. After achieving adsorption/desorption equilibrium (by keeping the $0.05 \%$ $\mathrm{TiO}_{2}$ solution for $2 \mathrm{~h}$ in dark), 1 sun (AM $1.5 \mathrm{G} 100 \mathrm{~mW} / \mathrm{cm}^{2}$ ) irradiation was employed. During the light irradiation and vigorous stirring with $600 \mathrm{rpm}$, we extracted $1 \mathrm{~mL}$ of sample solution at each interval. After centrifuging the solutions, the concentration changes of supernatant were characterized by using a UV-VIS-NIR Spectrophotometer (UV-3600, SHIMADZU).

Photocatalytic hydrogen production was performed in a $100 \mathrm{~mL}$ Quartz reactor, of which openings were sealed with the silicon rubber septum. $100 \mathrm{mg}$ of catalyst was dispersed in $50 \mathrm{~mL}$ of $1 \mathrm{M} \mathrm{KHCO}_{3}$ solution. During the 1 sun (AM 1.5G $100 \mathrm{~mW} / \mathrm{cm}^{2}$ ) irradiation, the suspension solution was stirred continuously. To analyze the $\mathrm{H}_{2}$ production, we extracted $1 \mathrm{~mL}$ of gas from the reactor by using a glass syringe and injected the collected gas in a gas chromatography (7890A GC system, Agilent Technologies, Santa Clara, USA). Here, Ar gas was exploited as a carrier gas. The extraction and injection of generated gas were repeated at intervals.

In this study, a solar simulator (PEC-L01, PECCELL, Yokohama, Japan) was utilized as the light source. AM 1.5G filter was exploited for the 1 sun illumination with the full spectrum $(350-1100 \mathrm{~nm})$. The light intensity was calibrated by using a silicon reference cell (Fraunhofer ISE, Certificate No. CISE269). 


\subsection{Photoelectrochemical Measurement}

The current density to potential $(J-V)$ curves were obtained via the linear sweep voltammetry (LSV) mode using the three electrodes system with the standard calomel electrode as the reference electrode, $\mathrm{Pt}$ foil as the counter electrode and the working electrode. The measurement was carried out using a potentiostat (CHI 705E, CH Instruments, Austin, TX, USA). $1 \mathrm{M} \mathrm{KHCO}_{3}$ aqueous solution was utilized as the electrolyte. The solar simulator (PEC-L01, PECCELL) was also utilized as the light source. The working electrode was prepared by the following manner [27]: $3 \mathrm{wt} \%$ of solution was prepared by dispersing the photocatalyst powders in $1 \mathrm{~mL}$ of ethanol solvent. After adding $0.5 \mathrm{~mL}$ of ethyl cellulose solution (10 wt \% aq.), the vigorous stirring was conducted for $8 \mathrm{~h}$ at $80^{\circ} \mathrm{C}$. Then, $0.16 \mathrm{~mL}$ of $\alpha$-terpineol was added. To make a paste, the stirring process was continued for $16 \mathrm{~h}$ more. The doctor blade method was used to coat the paste uniformly on the pre-cleaned FTO glass. Then, the annealing process was conducted at $500{ }^{\circ} \mathrm{C}$ for $30 \mathrm{~min}$.

\section{Results and Discussion}

\subsection{Morphology Characterization}

The importance of crystallinity in the metal oxide photocatalysts has been widely studied. The photochemical energy conversion efficiency can be determined by their crystallinity [28,29]. In the XRD patterns (Figure 1a), the crystalline $\mathrm{TiO}_{2}$ in anatase/rutile mixed crystalline phase (JCPDS\# 21-1272 for anatase, JCPDS\# 21-1276 for rutile) was observed for bare $\mathrm{TiO}_{2}$ nanoparticles. Considering the phase transition behavior of $\mathrm{TiO}_{2}$, [30] the annealing process at $750{ }^{\circ} \mathrm{C}$ resulted in the anatase/rutile mixed crystalline phase. However, the rutile phase peaks were diminished in $\mathrm{TP}-\mathrm{TiO}_{2}$ while the anatase phase and strong titanyl phosphate (JCPDS\# 35-802) peaks were observed, even the same annealing process was conducted at $750{ }^{\circ} \mathrm{C}$ for $\mathrm{TP}_{-} \mathrm{TiO}_{2}$. The suppressed phase transformation between anatase and rutile is attributed to the phosphate anions, of which good affinity to Ti atoms hindered the phase transformation of $\mathrm{TiO}_{2}$ [31]. Even the phosphate anions induced these significant changes in crystallinity, no significant changes in morphology were not characterized in SEM images (Figure $1 \mathrm{~b}$ and c). However, a slight increase in the size of overall particles was observed in $\mathrm{TP}^{-\mathrm{TiO}_{2}}$. The estimated particle size was avg. $51 \mathrm{~nm}( \pm 27)$ for bare $\mathrm{TiO}_{2}$ and avg. $58 \mathrm{~nm}( \pm 18)$ for $\mathrm{TP}^{-\mathrm{TiO}_{2}}$. This presumably resulted from the phosphate anions. HR-TEM images of $\mathrm{TP}_{-} \mathrm{TiO}_{2}$ (Figure $1 \mathrm{~d}$ and e) demonstrate that the surface of $\mathrm{TP}-\mathrm{TiO}_{2}$ was conformally passivated by the titanyl phosphate layer of which thickness was ca. $5 \mathrm{~nm}$. The fringe pattern in Figure 1e and the reduced fast Fourier transform (FFT) pattern in the insert image indicate that the core $\mathrm{TiO}_{2}$ is composed of the anatase phase. The anatase (101) was clearly defined by the distinct lattice space of $0.35 \mathrm{~nm}$. For further determination of this $\mathrm{TiO}_{2}$-core @ titanyl phosphate-shell structure, the elemental mapping of $\mathrm{Ti}$, $\mathrm{O}$, and $\mathrm{P}$ atoms was performed using TEM-EDS (Figure 1f). As shown in the high angle annular dark field scanning (HAADF) TEM image, the mapping was focused on the surface passivation layer. This elemental mapping image shows that all elements (Ti, $\mathrm{O}$ and $\mathrm{P}$ atoms) are well dispersed in the passivation layer, which implies that the surface of $\mathrm{TP}^{-\mathrm{TiO}_{2}}$ is conformally passivated by titanyl phosphate. 

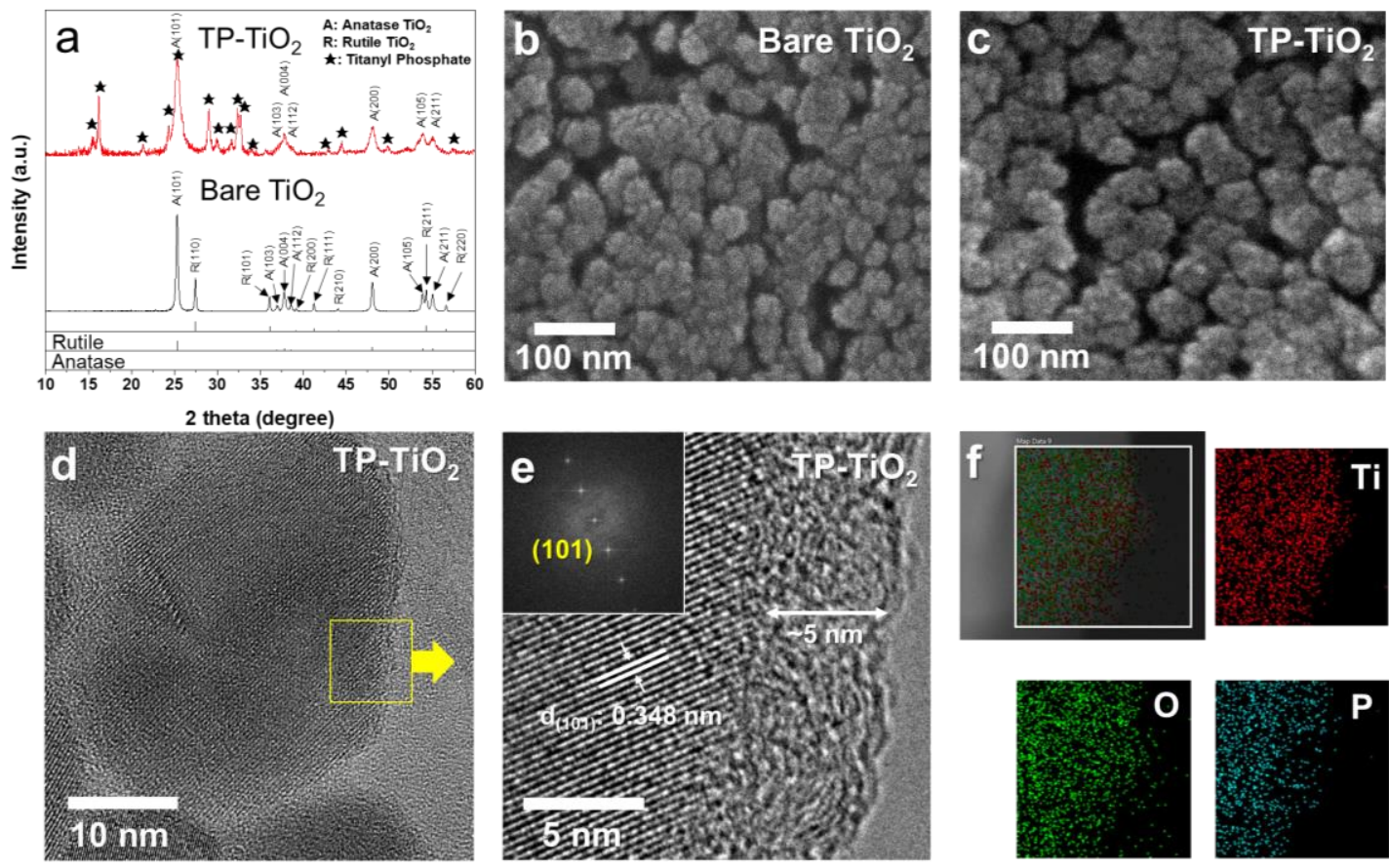

Figure 1. (a) XRD pattern of bare and $\mathrm{TP}-\mathrm{TiO}_{2}$. SEM images of bare (a) and $\mathrm{TP}-\mathrm{TiO}_{2}(\mathbf{b})$. (d) and (e) HR-TEM images of TP-TiO 2 . The inserted image is a reduced FFT pattern. (f) HAADF TEM image and EDS elemental mapping of $\mathrm{Ti}, \mathrm{O}$ and $\mathrm{P}$ atoms for $\mathrm{TP}-\mathrm{TiO}_{2}$.

\subsection{Chemical Modification}

For the sake of understanding the chemical modification, XPS characterization was performed as shown in Figure 2. The $\mathrm{C} 1 \mathrm{~s}$ XPS spectra of bare and $\mathrm{TP}-\mathrm{TiO}_{2}$ were utilized to reference the measured XPS results, where the binding energy of major C-C peaks are $284.8 \mathrm{eV}$ (Supplementary Figure S1). The positive shift of Ti $2 \mathrm{p}_{1 / 2}$ and Ti $2 \mathrm{p}_{3 / 2}$ peaks of TP-TiO $\mathrm{T}_{2}$ were observed in the Ti $2 \mathrm{p}$ XPS spectra (Figure 2a). The shift in Ti $2 p$ can be attributed to the ameliorated surface states [32,33]. This positive shift of Ti $2 p$ demonstrates that the Ti-O-P-O bonds were successfully formed on the surface of the $\mathrm{TiO}_{2}$ core particle, and resulted in the reduction of trap states originated from $\mathrm{Ti}^{3+}$ defects. The O $1 \mathrm{p}$ XPS spectra are displayed in Figure 2b. Two dominant peaks of bare $\mathrm{TiO}_{2}$ at 530.1 and $531.6 \mathrm{eV}$ are assigned to the lattice oxygen $\left(\mathrm{O}_{\mathrm{L}}\right)$ and surface oxygen $\left(\mathrm{O}_{\mathrm{S}}\right)$, respectively. Here, the lattice oxygen indicates Ti-O-Ti chain. However, the $\mathrm{TP}-\mathrm{TiO}_{2}$ exhibited four peaks at 530.1, 531.1, 531.6, and $532.9 \mathrm{eV}$. The newly arising peak at $531.1 \mathrm{eV}$, corresponding to Ti-O-P bond, demonstrates the formation of titanyl phosphate on the surface of $\mathrm{TiO}_{2}$ [34]. Moreover, the sharper $\mathrm{O}_{\mathrm{S}}$ peak centered at $531.6 \mathrm{eV}$ is also attributed to the $\mathrm{OH}$ species or $\mathrm{O}$ vacancies that originated from the titanyl phosphate groups [35]. Considering the disordered structure of surface titanyl phosphate layer in the TEM image (Figure 2e), the phosphate anion groups can induce -OH groups or $\mathrm{O}$ vacancies on $\mathrm{TP}^{-\mathrm{TiO}_{2}}$. In addition, the shoulder peak at $532.9 \mathrm{eV}$, can be attributed to chemisorbed oxygen species $\left(\mathrm{O}_{\mathrm{C}}\right)$ such as $\mathrm{CO}_{2}$ or $\mathrm{H}_{2} \mathrm{O}$ [36]. During the sol-gel process, the structure determining agent (i.e. PEG) can be bounded to the phosphate anion species via hydrogen bonding. Therefore, the carbon or oxygen related species (including $\mathrm{CO}_{2}$ or carboxylic groups) can be remained on the surface of $\mathrm{TP}^{-\mathrm{TiO}_{2}}$ after performing the annealing process. As shown in C 1s XPS (Figure S1), the slight increase in C-O (ca. $286.5 \mathrm{eV}$ ) and $\mathrm{C}=\mathrm{O}$ (ca. $288.5 \mathrm{eV}$ ) peaks were observed in $\mathrm{TP}-\mathrm{TiO}_{2}$, which implies that the oxygen species can be adsorbed onto $\mathrm{TP}^{-\mathrm{TiO}_{2}}$ [7]. P 2p XPS is shown in Figure 2c, where TP- $\mathrm{TiO}_{2}$ has two sharp peaks at 133.0 and $133.9 \mathrm{eV}$ corresponding to $\mathrm{P} 2 \mathrm{p}_{3 / 2}$ and $\mathrm{P} 2 \mathrm{p}_{1 / 2}$, respectively. These peaks can be assigned to the monodentate coordinated phosphate anion $\left(\mathrm{PO}_{4}{ }^{3-}\right)$, when it comes to the binding energies of $\mathrm{Na}_{2} \mathrm{HPO}_{4}(133.1 \mathrm{eV})$ and $\mathrm{NaH}_{2} \mathrm{PO}_{4}$ $(133.9 \mathrm{eV})$ [23]. Additional T-P bond was not observed in the XPS spectrum. 



Figure 2. (a) Ti 2p; (b) O 1s; and (c) P 2p XPS spectra of bare and $\mathrm{TP}^{-\mathrm{TiO}_{2}}$.

\subsection{Photocatalytic Performance}

The photocatalytic activity was investigated via the photodegradation experiment using rhodamine $\mathrm{B}$ aqueous solution. In Figure $3 \mathrm{a}, \mathrm{TP}-\mathrm{TiO}_{2}$ shows outstanding photocatalytic activity comparing to bare $\mathrm{TiO}_{2}$. In order to calculate their rate constants, natural logarithmic plots were prepared as shown in Figure $3 \mathrm{~b}$. By using the first order reaction rate equation $\left(C / C_{0}=\exp (-k t)\right)$, the rate constants $(k)$ are calculated [27]. $\mathrm{TP}-\mathrm{TiO}_{2}$ shows approximately 3 -folds higher $k$ value than bare $\mathrm{TiO}_{2}$. Furthermore, Figure $3 \mathrm{c}$ shows the performances of photocatalytic hydrogen production. Since the surface phosphate groups can promote the formation of hydroxyl radicals in water, $1 \mathrm{M}$ $\mathrm{KHCO}_{3}$ aqueous solution was exploited as the electrolyte to stabilize the $\mathrm{H}_{2} \mathrm{O}_{2}$ production and induce the 2-electron pathway for water splitting [23,37-40]. Significantly higher photocatalytic hydrogen production rate $\left(86.7 \mu \mathrm{mol} \mathrm{h}^{-1} \mathrm{~g}^{-1}\right.$ for $\mathrm{TP}_{-} \mathrm{TiO}_{2}$ and $46.1 \mu \mathrm{mol} \mathrm{h}^{-1} \mathrm{~g}^{-1}$ for bare $\left.\mathrm{TiO}_{2}\right)$ was achieved. Moreover, $\mathrm{TP}-\mathrm{TiO}_{2}$ also shows much stable photocatalytic activity than bare $\mathrm{TiO}_{2}$ due to the conformal passivation of titanyl phosphate. After continuous operation for $24 \mathrm{~h}$, negligible changes in the production rate was observed in $\mathrm{TP}^{-\mathrm{TiO}_{2}}$, whereas visible changes were shown by bare $\mathrm{TiO}_{2}$. TEM image of $\mathrm{TP}-\mathrm{TiO}_{2}$ after $24 \mathrm{~h}$ of operation (Supplementary Figure S2) shows the long-term stability of titanyl phosphate layer. The surface modification using the phosphate species can generate the negative electrostatic field, which facilitates the efficient charge migration. The negative electrostatic field also can activate the formation of hydrogen bond between phosphate anion and water molecule. This promotes the adsorption of water molecules at the surface of photocatalysts and the generation of hydroxyl radical, resulting in high efficient photocatalytic properties [20,22,23]. Moreover, the charge recombination was suppressed since the charge trap states of $\mathrm{TiO}_{2}$ were ameliorated by the surface titanyl phosphate passivation layer. It is noteworthy that no significant changes in the UV-Vis absorbance spectra were observed (Supplementary Figure S3). This implies that the surface passivation layer with the disordered structure does not influence the light harvesting property of photocatalyst [41]. To investigate the efficient charge migration properties, the photoelectrochemical (PEC) response was characterized using the three electrodes system, of which working electrode was comprised of the $\mathrm{TiO}_{2}$ photocatalysts (Supplementary Figure S4). $1 \mathrm{M} \mathrm{KHCO}_{3}$ aqueous solution $(\mathrm{pH}$ 7.4) was also used as the electrolyte. The significantly enhanced photocurrent density value of $\mathrm{TP}-\mathrm{TiO}_{2}$ was resulted from not only the modified surface catalytic kinetics, but also the suppressed charge recombination and promoted charge migration [41]. Additionally, the external quantum 
efficiency (EQE) spectra were investigated to demonstrate the enhanced performance of $\mathrm{TP}^{-\mathrm{TiO}_{2}}$ in Supplementary Figure S4b.
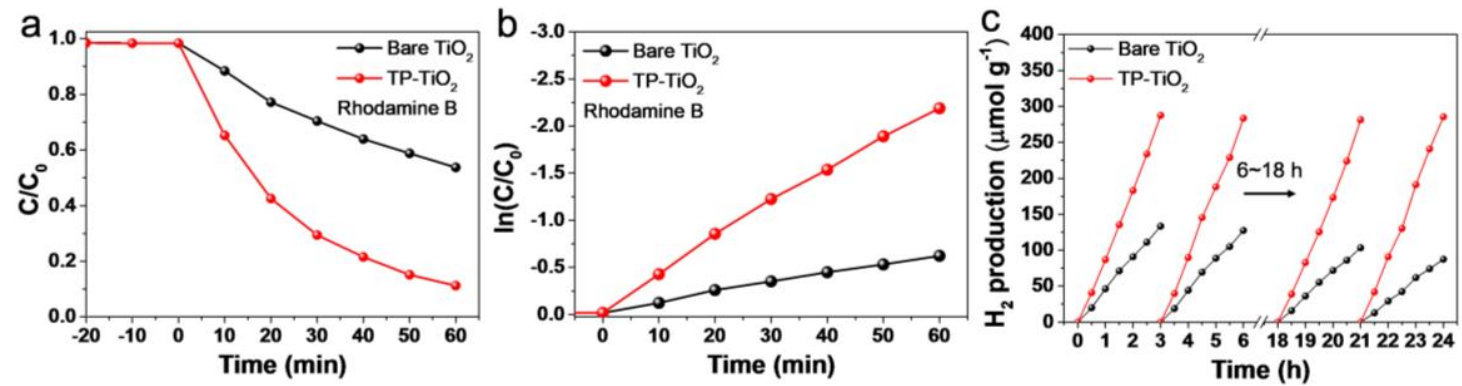

Figure 3. (a) Concentration changes in rhodamine B aqueous solution by photodegradation; (b) Natural logarithmic plots for the study of the kinetics of rhodamine B photodegradation profiles;

(c) Photocatalytic hydrogen production and cycling performance during $24 \mathrm{~h}$ of continuous reaction in the presence of $1 \mathrm{M} \mathrm{KHCO}_{3}$.

\section{Conclusions}

The $\mathrm{TiO}_{2}$ photocatalysts were conformally modified by the titanyl phosphate passivation layer with a thickness of ca. $5 \mathrm{~nm}$. The use of a facile surfactant-assisted sol-gel process facilitated the formation of titanyl phosphate on the surface of $\mathrm{TiO}_{2}$ nanoparticles. The phosphate anions are strongly bound onto the surface Ti atoms with oxygen bridges, inducing the Ti-O-P-O bonds. Thereby, the surface titanyl phosphate bonds resulted in the reduction of trap states originated from $\mathrm{Ti}^{3+}$ defects. These strong bonds enable the long-term photochemical performance in liquid electrolytes with enhanced photocatalytic activities. Moreover, the titanyl phosphate contributed to the production and stabilization of hydroxyl radicals on the surface of $\mathrm{TiO}_{2}$ nanoparticles, which facilitated the efficient photooxidation of the organic pollutants. Furthermore, the significantly enhanced photocatalytic hydrogen production performance was observed by the titanyl phosphate modified $\mathrm{TiO}_{2}$. Consequently, high photocatalytic activity was achieved by introducing the titanyl phosphate surface passivation layer. The demonstrated titanyl phosphate modification enables the conformal passivation of $\mathrm{TiO}_{2}$ photocatalysts with tunable properties, which is conducive to diverse photochemical conversion applications.

Supplementary Materials: The following are available online at http:/ /www.mdpi.com/2076-3417/8/8/1402/s1, Figure S1: C 1s XPS spectra of bare and $\mathrm{TP}-\mathrm{TiO}_{2}$, Figure S2: TEM image of $\mathrm{TP}-\mathrm{TiO}_{2}$ after carrying out the photocatalytic $\mathrm{H}_{2}$ production experiment for 24 hours, Figure S3: UV-Vis absorbance spectra and Tauc plot (insert) of bare and $\mathrm{TP}-\mathrm{TiO}_{2}$, Figure S4: Current density to potential $(J-V)$ curves, EQE and IQE spectra of bare and $\mathrm{TP}-\mathrm{TiO}_{2}$ under on/off chopped 1 sun irradiation.

Acknowledgments: The authors acknowledge the support of the NRF of Korea (NRF-2018R1D1A1B07050875).

Conflicts of Interest: The authors declare no conflict of interest.

\section{References}

1. Fujishima, A.; Honda, K. Electrochemical photolysis of water at a semiconductor electrode. Nature 1972, 238, 37-38. [CrossRef] [PubMed]

2. O'Regan, B.; Grätzel, M. A low-cost, high-efficiency solar cell based on dye-sensitized colloidal TiO $\mathrm{T}_{2}$ films. Nature 1991, 353, 737-740. [CrossRef]

3. Bard, A.J. Photoelectrochemistry. Science 1980, 207, 139-144. [CrossRef] [PubMed]

4. Kim, J.K.; Jang, J.-r.; Choi, N.; Hong, D.; Nam, C.-H.; Yoo, P.J.; Park, J.H.; Choe, W.-S. Lysozyme-mediated biomineralization of titanium-tungsten oxide hybrid nanoparticles with high photocatalytic activity. Chem. Commun. 2014, 50, 12392-12395. [CrossRef] [PubMed] 
5. Crossland, E.J.W.; Noel, N.; Sivaram, V.; Leijtens, T.; Alexander-Webber, J.A.; Snaith, H.J. Mesoporous TiO 2 single crystals delivering enhanced mobility and optoelectronic device performance. Nature 2013, 495, 215-219. [CrossRef] [PubMed]

6. Giordano, F.; Abate, A.; Baena, J.P.C.; Saliba, M.; Matsui, T.; Im, S.H.; Zakeeruddin, S.M.; Nazeeruddin, M.K.; Hagfeldt, A.; Graetzel, M. Enhanced electronic properties in mesoporous $\mathrm{TiO}_{2}$ via lithium doping for high-efficiency perovskite solar cells. Nat. Commun. 2016, 7. [CrossRef] [PubMed]

7. Kim, J.K.; Chai, S.U.; Cho, Y.; Cai, L.L.; Kim, S.J.; Park, S.; Park, J.H.; Zheng, X.L. Ultrafast flame annealing of $\mathrm{TiO}_{2}$ paste for fabricating dye-sensitized and perovskite solar cells with enhanced efficiency. Small 2017, 13. [CrossRef] [PubMed]

8. Kim, J.K.; Shin, K.; Cho, S.M.; Lee, T.W.; Park, J.H. Synthesis of transparent mesoporous tungsten trioxide films with enhanced photoelectrochemical response: Application to unassisted solar water splitting. Energy Environ. Sci. 2011, 4, 1465-1470. [CrossRef]

9. Onotri, L.; Race, M.; Clarizia, L.; Guida, M.; Alfè, M.; Andreozzi, R.; Marotta, R. Solar photocatalytic processes for treatment of soil washing wastewater. Chem. Eng. J. 2017, 318, 10-18. [CrossRef]

10. Malato, S.; Blanco, J.; Vidal, A.; Alarcón, D.; Maldonado, M.I.; Cáceres, J.; Gernjak, W. Applied studies in solar photocatalytic detoxification: An overview. Sol. Energy 2003, 75, 329-336. [CrossRef]

11. Aguirre, M.E.; Zhou, R.; Eugene, A.J.; Guzman, M.I.; Grela, M.A. $\mathrm{Cu}_{2} \mathrm{O} / \mathrm{TiO}_{2}$ heterostructures for $\mathrm{CO}_{2}$ reduction through a direct Z-scheme: Protecting $\mathrm{Cu}_{2} \mathrm{O}$ from photocorrosion. Appl. Catal. B: Environ. 2017, 217, 485-493. [CrossRef]

12. Park, H.; Park, Y.; Kim, W.; Choi, W. Surface modification of $\mathrm{TiO}_{2}$ photocatalyst for environmental applications. J. Photochem. Photobio. C: Photochem. Rev. 2013, 15, 1-20. [CrossRef]

13. Naldoni, A.; Allieta, M.; Santangelo, S.; Marelli, M.; Fabbri, F.; Cappelli, S.; Bianchi, C.L.; Psaro, R.; Dal Santo, V. Effect of nature and location of defects on bandgap narrowing in black $\mathrm{TiO}_{2}$ nanoparticles. J. Am. Chem. Soc. 2012, 134, 7600-7603. [CrossRef] [PubMed]

14. Liu, G.; Yin, L.C.; Wang, J.Q.; Niu, P.; Zhen, C.; Xie, Y.P.; Cheng, H.M. A red anatase $\mathrm{TiO}_{2}$ photocatalyst for solar energy conversion. Energy Environ. Sci. 2012, 5, 9603-9610. [CrossRef]

15. Li, Y.G.; Zhu, L.P.; Guo, Y.M.; Song, H.; Lou, Z.R.; Ye, Z.Z. A new type of hybrid nanostructure: Complete photo-generated carrier separation and ultrahigh photocatalytic activity. J. Mater. Chem. A 2014, 2, 14245-14250. [CrossRef]

16. Gao, L.; Li, Y.; Ren, J.; Wang, S.; Wang, R.; Fu, G.; Hu, Y. Passivation of defect states in anatase $\mathrm{TiO}_{2}$ hollow spheres with mg doping: Realizing efficient photocatalytic overall water splitting. Appl. Catal. B: Environ. 2017, 202, 127-133. [CrossRef]

17. Tong, H.; Ouyang, S.X.; Bi, Y.P.; Umezawa, N.; Oshikiri, M.; Ye, J.H. Nano-photocatalytic materials: Possibilities and challenges. Adv. Mater. 2012, 24, 229-251. [CrossRef] [PubMed]

18. Minero, C.; Mariella, G.; Maurino, V.; Pelizzetti, E. Photocatalytic transformation of organic compounds in the presence of inorganic anions. 1. Hydroxyl-Mediated and Direct Electron-Transfer reactions of Phenol on a Titanium Dioxide-Fluoride system. Langmuir 2000, 16, 2632-2641. [CrossRef]

19. Körösi, L.; Papp, S.; Bertóti, I.; Dékány, I. Surface and bulk composition, structure, and photocatalytic activity of phosphate-modified $\mathrm{TiO}_{2}$. Chem. Mater. 2007, 19, 4811-4819. [CrossRef]

20. He, T.; Weng, Y.; Yu, P.; Liu, C.; Lu, H.; Sun, Y.; Zhang, S.; Yang, X.; Liu, G. Bio-template mediated in situ phosphate transfer to hierarchically porous $\mathrm{TiO}_{2}$ with localized phosphate distribution and enhanced photoactivities. J. Phys. Chem. C 2014, 118, 4607-4617. [CrossRef]

21. Shao, G.-S.; Wang, F.-Y.; Ren, T.-Z.; Liu, Y.; Yuan, Z.-Y. Hierarchical mesoporous phosphorus and nitrogen doped titania materials: Synthesis, characterization and visible-light photocatalytic activity. Appl. Catal. B: Environ. 2009, 92, 61-67. [CrossRef]

22. Jing, L.; Zhou, J.; Durrant, J.R.; Tang, J.; Liu, D.; Fu, H. Dynamics of photogenerated charges in the phosphate modified $\mathrm{TiO}_{2}$ and the enhanced activity for photoelectrochemical water splitting. Energy Environ. Sci. 2012, 5, 6552-6558. [CrossRef]

23. Zhao, D.; Chen, C.C.; Wang, Y.F.; Ji, H.W.; Ma, W.H.; Zang, L.; Zhao, J.C. Surface modification of $\mathrm{TiO}_{2}$ by phosphate: Effect on photocatalytic activity and mechanism implication. J. Phys. Chem. C 2008, 112, 5993-6001. [CrossRef] 
24. Yu, J.C.; Zhang, L.Z.; Zheng, Z.; Zhao, J.C. Synthesis and characterization of phosphated mesoporous titanium dioxide with high photocatalytic activity. Chem. Mater. 2003, 15, 2280-2286. [CrossRef]

25. Ortiz-Islas, E.; Gomez, R.; Lopez, T.; Navarrete, J.; Aguilar, D.H.; Quintana, P. Effect of the crystallite size in the structural and textural properties of sulfated and phosphated titania. Appl. Surf. Sci. 2005, 252, 807-812. [CrossRef]

26. Connor, P.A.; McQuillan, A.J. Phosphate adsorption onto $\mathrm{TiO}_{2}$ from aqueous solutions: An in situ internal reflection infrared spectroscopic study. Langmuir 1999, 15, 2916-2921. [CrossRef]

27. Kim, J.K.; Bae, S.; Kim, W.; Jeong, M.J.; Lee, S.H.; Lee, C.-L.; Choi, W.K.; Hwang, J.Y.; Park, J.H.; Son, D.I. Nano carbon conformal coating strategy for enhanced photoelectrochemical responses and long-term stability of ZnO quantum dots. Nano Energy 2015, 13, 258-266. [CrossRef]

28. Linsebigler, A.L.; Lu, G.Q.; Yates, J.T. Photocatalysis on $\mathrm{TiO}_{2}$ surfaces—principles, mechanisms, and selected results. Chem. Rev. 1995, 95, 735-758. [CrossRef]

29. Zhang, Y.Y.; Chen, J.Z.; Li, X.J. Preparation and photocatalytic performance of anatase/rutile mixed-phase $\mathrm{TiO}_{2}$ nanotubes. Catal. Lett. 2010, 139, 129-133. [CrossRef]

30. Nolan, N.T.; Seery, M.K.; Pillai, S.C. Spectroscopic investigation of the anatase-to-rutile transformation of sol-gel-synthesized $\mathrm{TiO}_{2}$ photocatalysts. J. Phys. Chem. C 2009, 113, 16151-16157. [CrossRef]

31. Antonelli, D.M.; Ying, J.C. Synthesis of hexagonally packed mesoporous $\mathrm{TiO}_{2}$ by a modified sol-gel method. Angew. Chem. Int. Ed. 1995, 34, 2014-2017. [CrossRef]

32. Yermakov, A.Y.; Zakharova, G.S.; Uimin, M.A.; Kuznetsov, M.V.; Molochnikov, L.S.; Konev, S.F.; Konev, A.S.; Minin, A.S.; Mesilov, V.V.; Galakhov, V.R.; et al. Surface magnetism of cobalt-doped anatase $\mathrm{TiO}_{2}$ nanopowders. J. Phys. Chem. C 2016, 120, 28857-28866. [CrossRef]

33. Jun, P.; Duong, T.; Zhou, X.Z.; Shen, H.P.; Wu, Y.L.; Mulmudi, H.K.; Wan, Y.M.; Zhong, D.Y.; Li, J.T.; Tsuzuki, T.; Weber, K.J.; et al. Efficient indium-doped Tix electron transport layers for high-performance perovskite solar cells and perovskite-silicon tandems. Adv. Energy Mater. 2017, 7, 1601768. [CrossRef]

34. Boukhvalov, D.W.; Korotion, D.M.; Efremov, A.V.; Kurmaev, E.Z.; Borchers, C.; Zhidkov, I.S.; Gunderov, D.V.; Valiev, D.V.; Gavrilov, N.V.; Cholakh, S.O. Modification of titanium and titanium dioxide surfaces by ion implantation: Combined XPS and DFT study. Phys. Status Solidi B 2015, 252, 748-754. [CrossRef]

35. Duan, X.; Liu, J.; Chen, Y.; Li, Z.; Zhu, P.; Jiang, H. Modification of $\mathrm{RbTiOPO}_{4}(001)$ crystal surface induced by $\mathrm{Ar}^{+}$ion bombardment: X-ray photoelectron spectroscopy and first-principles studies. Vacuum 2018, 147, 38-44. [CrossRef]

36. Zhang, X.; Qin, J.; Xue, Y.; Yu, P.; Zhang, B.; Wang, L.; Liu, R. Effect of aspect raTi and surface defects on the photocatalytic activity of ZnO nanorods. Sci. Rep. 2014, 4, 4596. [CrossRef] [PubMed]

37. Kim, J.K.; Shi, X.J.; Jeong, M.J.; Park, J.; Han, H.S.; Kim, S.H.; Guo, Y.; Heinz, T.F.; Fan, S.H.; Lee, C.L.; et al. Enhancing $\mathrm{Mo:Bivo} 4$ solar water splitting with patterned Au nanospheres by plasmon-induced energy transfer. Adv. Energy Mater. 2018, 8. [CrossRef]

38. Liu, J.; Liu, Y.; Liu, N.; Han, Y.; Zhang, X.; Huang, H.; Lifshitz, Y.; Lee, S.-T.; Zhong, J.; Kang, Z. Metal-free efficient photocatalyst for stable visible water splitting via a two-electron pathway. Science 2015, 347, 970-974. [CrossRef] [PubMed]

39. Dimitrijevic, N.M.; Vijayan, B.K.; Poluektov, O.G.; Rajh, T.; Gray, K.A.; He, H.; Zapol, P. Role of water and carbonates in photocatalytic transformation of $\mathrm{CO}_{2}$ to $\mathrm{CH}_{4}$ on titania. J. Am. Chem. Soc. 2011, 133, 3964-3971. [CrossRef] [PubMed]

40. Pilli, S.K.; Deutsch, T.G.; Furtak, T.E.; Brown, L.D.; Turner, J.A.; Herring, A.M. $\mathrm{BiVO}_{4} / \mathrm{CuWO}_{4}$ heterojunction photoanodes for efficient solar driven water oxidation. Phys. Chem. Chem. Phys. 2013, 15, 3273-3278. [CrossRef] [PubMed]

41. Kim, J.K.; Cho, Y.; Jeong, M.J.; Levy-Wendt, B.; Shin, D.; Yi, Y.; Wang, D.H.; Zheng, X.L.; Park, J.H. Rapid formation of a disordered layer on monoclinic $\mathrm{BiVO}_{4}$ : Co-catalyst-free photoelectrochemical solar water splitting. Chemsuschem 2018, 11, 933-940. [CrossRef] [PubMed]

(C) 2018 by the author. Licensee MDPI, Basel, Switzerland. This article is an open access article distributed under the terms and conditions of the Creative Commons Attribution (CC BY) license (http:/ / creativecommons.org/licenses/by/4.0/). 